\title{
PRODUCTION PLANNING AND CONTROL AS-IMAGINED AND AS-DONE: THE GAP AT THE LOOK-AHEAD LEVEL
}

\author{
Douglas Comassetto Hamerski ${ }^{1}$, Luara Lopes de Araujo Fernandes ${ }^{2}$, Mattheus \\ Souza Porto ${ }^{3}$, Tarcisio Abreu Saurin ${ }^{4}$, Carlos Torres Formoso ${ }^{5}$, and Dayana \\ Bastos Costa ${ }^{6}$
}

\begin{abstract}
The Last Planner ${ }^{\circledR}$ System (LPS) of Production Control is widely acknowledged as fit to tackle the complexity of construction projects. However, the implications of complexity in the implementation of LPS itself have not been investigated. Those implications are investigated in this paper by exploring the gap between production planning and controlas-imagined and as-done at the look-ahead level. For that purpose, a case study was conducted in the refurbishment of a department store in which the LPS was implemented. Data collection involved document analysis, participant observation at the look-ahead and short-term planning meetings, and unstructured interviews. The Functional Resonance Analysis Method (FRAM) was used for modeling variability and interactions between the managerial functions at the look-ahead planning level. Results indicated several differences between production planning and control-as-imagined and as-done, which reflect hidden activities required for the removal of constraints. These activities took time and effort from managers and therefore they can partly explain why the LPS was not strictly followed as-imagined in theory.
\end{abstract}

\section{KEYWORDS}

Last Planner® System, look-ahead planning, production planning and control, complexity, FRAM.

$1 \quad$ PhD Student, Postgraduate Program in Civil Eng.: Construction and Infrastructure, Federal University of Rio Grande do Sul, Porto Alegre, Brazil, douglas_hamerski@ hotmail.com, orcid.org/0000-0002$\underline{3804-4047}$

2 PhD Student, Postgraduate Program in Civil Engineering, Federal University of Bahia, Salvador, Brazil, luara.fernandes@gmail.com, orcid.org/0000-0003-4041-8025

3 MSc Student, Postgraduate Program in Civil Eng.: Construction and Infrastructure, Federal University of Rio Grande do Sul, Porto Alegre, Brazil, mattheus_porto@ hotmail.com, orcid.org/0000-0003-1754$\underline{7718}$.

$4 \quad$ Associate Professor, Industrial Engineering and Transportation Department, Federal University of Rio Grande do Sul, Brazil, saurin@ufrgs.br, orcid.org/0000-0003-2929-5888

5 Professor, Postgraduate Program in Civil Eng.: Construction and Infrastructure, Federal University of Rio Grande do Sul, Porto Alegre, Brazil, formoso@ufrgs.br, orcid.org/0000-0002-4772-3746

6 Associate Professor, School of Engineering, Department of Structural and Construction Engineering, Federal University of Bahia, Salvador, Brazil, dayanabcosta@ufba.br, orcid.org/0000-0002-1457$\underline{6401}$. 


\section{INTRODUCTION}

Construction projects can be usually regarded as complex systems (Bertelsen 2003), as they have many interrelated components (e.g. stages, technologies, stakeholders, etc.) which also interact with their environment (Dekker et al. 2013). In turn, the Last Planner System (LPS) is a production planning and control model, which is based on Lean concepts and principles that have been adapted from repetitive manufacturing into the construction domain (Ballard and Tommelein 2012). The LPS overcomes, to some extent, the limitations of traditional project management approaches (Koskela and Howell 2002) and has been associated with successful outcomes when applied to complex construction projects (Castillo et al. 2018).

The removal of constraints is a core process for the production of reliable plans in the LPS (Hamzeh et al. 2012). It is carried out at the look-ahead planning level, which typically has a planning horizon from 4 to 12 weeks and aims at making ready work packages, i.e., free of pending constraints so as they can be assigned to production teams in the short-term planning level (Ballard, 2000). Constraints may be related to labor, space, equipment, design, safety, among other resources. In fact, the same work package can be associated with several constraints and therefore there may be a non-linear relationship between the number of work packages and the number of constraints. Furthermore, the removal of constraints is likely to be recursive as the removal of a primary constraint (e.g. equipment) may trigger the need for removing other upstream constraints (e.g. maintenance of existing equipment). As such, it is reasonable to expect that the removal of constraints is also a complex process itself, likewise other LPS activities.

In this paper, this complexity is investigated in light of the concepts of work-asimagined and work-as-done, which were proposed by Hollnagel (2012). Work-asimagined (WAI) refers to the various assumptions, explicit or implicit, that people have about how work should be done, being often prescribed in procedures or standards. By contrast, work-as-done (WAD) refers to how something is actually done, either in a specific case or routinely (Hollnagel 2015). Previous studies, both in the construction industry (Penaloza et al. 2020) and in lean manufacturing systems (Soliman and Saurin 2020), have shown that the WAI and WAD concepts are applicable to managerial processes. Patriarca et al. (2021) coined the term WAx in order to convey the pervasive nature of these concepts. Understanding the gap between WAI and WAD is important for two main reasons: (i) it usually indicates that successful outcomes do not necessarily occur because people are behaving according to WAI (Hollnagel 2015); and (ii) wide gaps suggest considerable scope for improvement (Perkins et al. 2010).

Therefore, this study aims to investigate the gap between production planning and control-as-imagined (based on the original version of the LPS) and production planning and control-as-done (based on how it is applied in practice) at the look-ahead level. This investigation sheds light on taken-for-granted assumptions underlying the LPS.

\section{LITERATURE REVIEW}

\section{Construction Projects as Complex Socio-Technical Systems}

Complex socio-technical systems are formed by a large number of diverse and dynamically interacting elements, such as people, materials, equipment, and procedures (Hollnagel 2012). These interactions give rise to variability and uncertainty, which are present in most construction projects (Koskela 2000). 
In addition, some factors amplify the complexity of construction processes such as the fragmentation of the construction industry and the ever-growing demands for fast, safe, low cost, and high-quality projects (Gidado 1996). Thus, coping with complexity has been more and more part of everyday work in construction project management (Formoso et al. 2015).

Penaloza et al. (2020) pointed out some typical attributes of complexity in the construction industry, such as the gap between WAD and WAI, the influence of the external environment, and the interactions between construction stages. According to Melo and Costa (2019), the understanding of WAD in construction is often overlooked by managers; standardized operating procedures are devised for compliance purposes instead of providing useful guidance to those at the front line of construction activities.

\section{Functional Resonance Analysis Method (FRAM)}

Hollnagel (2004) conceived FRAM as a method to model complex systems. One of the main roles of FRAM is to model how different functions in socio-technical systems relate to each other (Hollnagel 2012). FRAM is based on the following main principles (Hollnagel 2012):

- The equivalence of successes and failures: things that go well and things that go wrong have the same causes. Acceptable and unacceptable outcomes are due to the ability of organizations and individuals to adjust to expected and unexpected circumstances.

- Approximate adjustments: work is continuously adjusted to the existing conditions (resources, time, tools, information, requirements, opportunities, conflicts, interruptions). These adjustments are made by individuals, groups, and organizations at all levels, and will be approximate rather than perfect.

- Emergence: the variability of multiple functions can combine in unexpected ways, leading to nonlinear effects. Thus, both failure and normal performance are emergent, rather than a resulting phenomenon, as they cannot be attributed or explained solely based on the functioning or non-functioning of specific components.

- Functional resonance: the combined everyday variability of various functions can sometimes create a functional resonance, thereby producing unexpected results. Functional resonance is the detectable variability (e.g. accidents or wastes) that otherwise remains hidden in everyday work.

FRAM application involves five steps (Hollnagel 2012):

1. To define the purpose of FRAM analysis, which can be, for example, an investigation of a past event, a risk assessment of a new system, or an evaluation of design changes;

2. To identify and describe the functions of the system according to six aspects (input, output, preconditions, resources, time, and control);

3. To describe the variability of the functions, taking into account what is expected to happen (or what happened, in the case of a past event) with the output of each function in terms of time (too early, on time, too late, not at all) and precision (precise, acceptable, imprecise); 
4. To aggregate the variability of individual functions, by assessing couplings between functions - couplings occur between the output of a function and any of the other aspects of downstream functions;

5. To devise practical measures for improving the work system design, if necessary.

\section{RESEARCH METHOD}

Case study was the research strategy adopted in this investigation. It is an appropriate strategy as this study aims to understand a current phenomenon in its context (Branski et al. 2010).

The initial step was the selection of a relevant case study. As the main selection criterion, we sought a construction project in which there was an explicit intention of fully using the LPS. Thus, a refurbishment project for a department store in Brazil, in which the LPS was implemented by demand of the owner, was selected. An additional benefit of choosing this project was the ease of access to data sources as one of the authors was involved in the planning and control process. The unit of analysis was the managerial functions that made up the look-ahead planning level. More specifically, this study focuses on those functions during the process of removing constraints.

Next, FRAM was used to model the functions involved in the removal of constraints, considering two work packages: (i) installation of the fire pipe support system; and (ii) mezzanine assembly. At the time of data collection, the former package had been $100 \%$ complete, while the latter was delayed. The first one was selected due to the wide variety of managerial functions that were necessary to make the work package ready. The second was selected as it involved much variability, which allowed the exploration of variability propagation across the planning process. Although the content of the work packages and the corresponding variabilities were different, the managerial functions involved in the removal of constraints were similar, thus facilitating meaningful comparisons.

The FRAM models reflected production planning and control-as-done at the lookahead level, which then set a basis for comparison with production planning and controlas-imagined by the original version of the LPS (Ballard 2000; Tommelein and Ballard 1997; Ballard and Howell 1998; Ballard and Howell 2003). The original LPS version was adopted as a basis for comparison because there were no formally documented standards specifying how construction planning was expected to occur in the construction project the contractor itself also adopted the original LPS as its imagined approach.

Three sources of evidence were used: documents, participant observations, and unstructured interviews (i.e. informal conversations). The documents analyzed were the look-ahead and short-term plans. Participant observations took place in planning and control meetings for 3 months. A total of 12 look-ahead meetings ( 2 hours each) and 12 short-term meetings ( 1 hour each) were attended by one of the researchers. Participant observations offered plenty of opportunities for unstructured interviews with some of the project staff in order to understand how managerial functions related to constraint removal were undertaken.

\section{Description of the Construction Project ANd The Existing PlanNing ANd Control System}

The study took place during the refurbishment of a commercial building in a shopping mall (department store focused on the sale of apparel) of approximately $1,500.00 \mathrm{~m}^{2}$. The majority of the work carried out in the construction site involved finishing activities. 
These activities were carried out by 15 subcontractors during a period of 3 months. Most of those activities had a high degree of interdependency between them.

The existing planning and control system was strongly based on lean principles and concepts. However, most of the participants involved in this construction project were experiencing the implementation of those principles and concepts for the first time. A Production System Design was developed before starting the construction stage. Lookahead planning meetings occurred every two weeks and short-term planning meetings were held weekly.

\section{RESULTS}

\section{FRAM MODELS}

Figure 1 presents a model of the functions involved in the removal of constraints for the work package "Installation of the fire pipe support system", while Figure 2 presents a similar model for the work package "Mezzanine assembly". In both models, 19 functions to make a work package ready were identified. The sequencing of the functions is represented from the top to the bottom and from the left to the right, while the functions are represented by hexagons. The hexagons with yellow borders are related to the preparation of the construction plans, which are part of long-term, look-ahead, and shortterm planning levels. The hexagon with red borders represents the work package execution, which is the last function of the models. In the traditional FRAM representation, the name of the functions appears inside each hexagon. However, for better visualization in this paper, a coding system was adopted (Table 1).

In Figures 1 and 2, the functions are categorized according to six of the preconditions for starting a construction task proposed by Koskela (2000), which are: construction design, components and materials, workers, equipment, connecting works, and space.

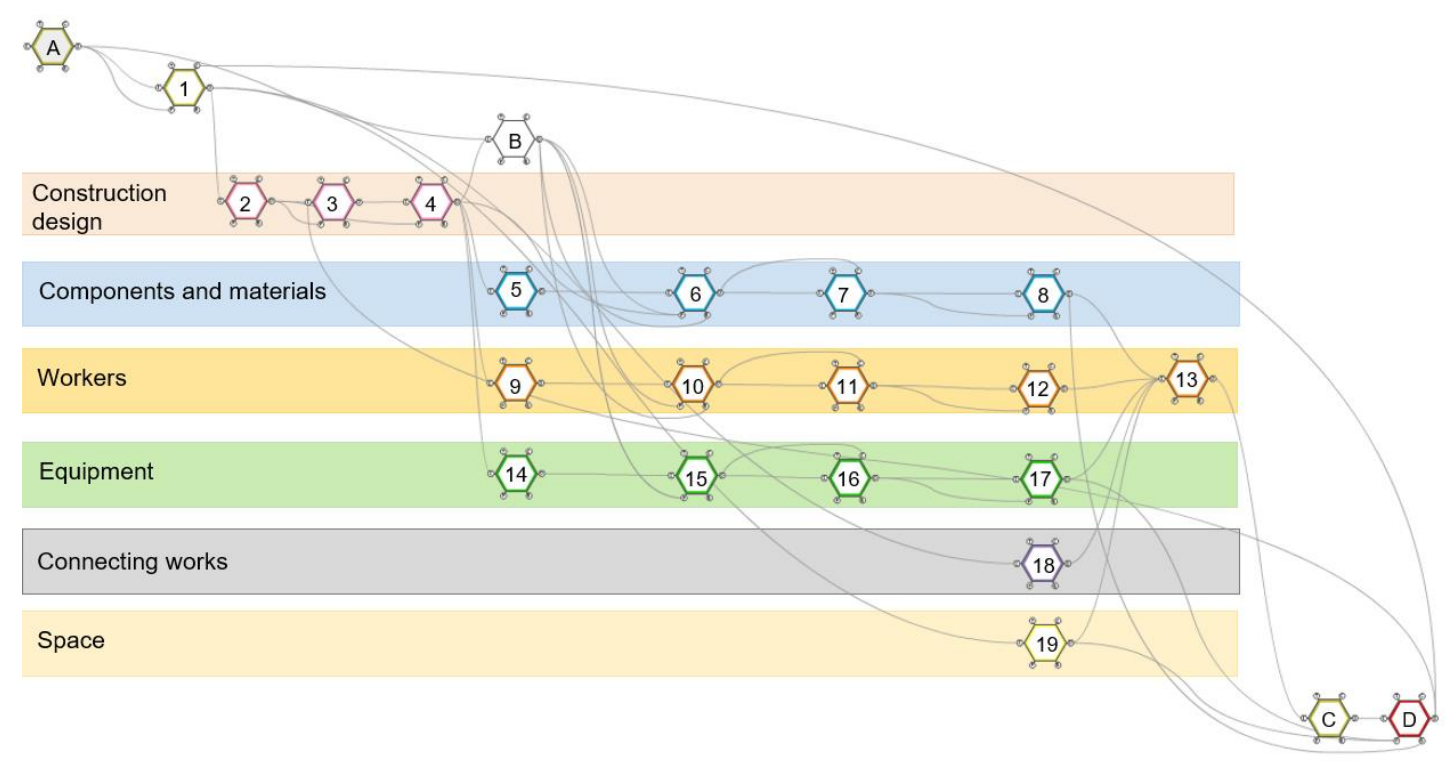

Figure 1 - Functional model for the removal of constraints: work package "Installation of the fire pipe support system" 


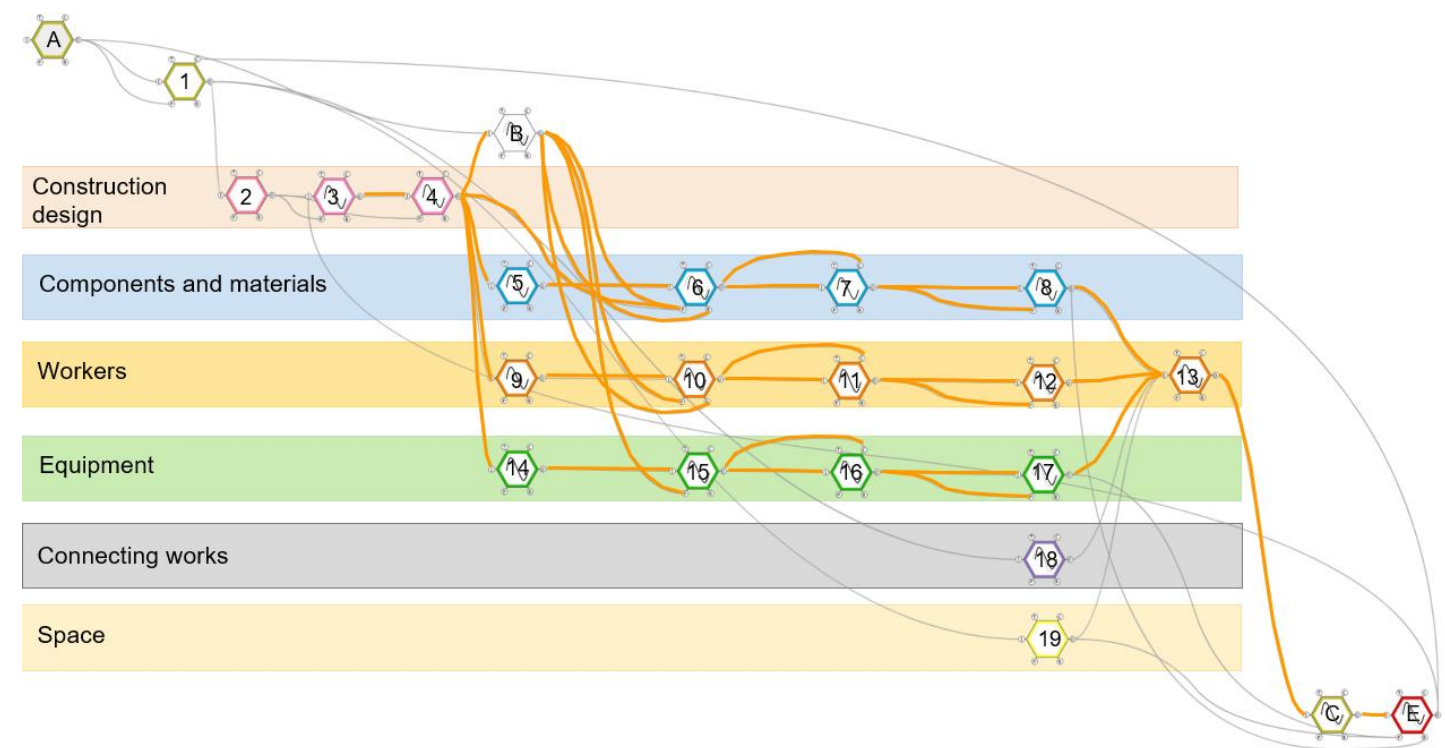

Figure 2 - Functional model for the removal of constraints: work package "Mezzanine assembly"

Table 1 - Names of the functions presented in Figures 1 and 2

Function
Produce long-term plan


The functions are coupled to each other through their outputs $(\mathrm{O})$ - they are connected to one or more of the other five aspects of the downstream functions, namely Input (I), Time (T), Precondition (P), Resource (R) or Control (C). In the studied models, the outputs of the initial function "Produce the long term-plan" are "Long-term meeting held", "Cash flow generation", and "The long-term plan". As presented in Figures 1 and 2, these outputs connect to the input and the precondition of the function "Produce the look-ahead plan", and the input of the function "Check financial resources availability".

The waves inside several functions indicate the existence of output variability and the yellow lines denote the propagation path (Figure 2). It is worth noting that, for the model in Figure 2, the work package was not completed due to a compatibility problem in the construction design. The problem started with variability in the output of the function "Study construction design" and propagated throughout almost all downstream functions, resulting in the non-completion of the work package. As the design incompatibility was not identified at its source, some managerial functions had to be performed twice to make the work package ready for the next short-term planning cycle (e.g. check workers availability, check the conclusion of previous work packages, and check space availability).

\section{DISCUSSION}

The results of this study pointed out that the production planning and control as-done was substantially different from the production planning and control as-imagined (Table 2).

Table 2 - Production planning and control-as-imagined x Production planning and control-as-done

\begin{tabular}{|c|c|}
\hline $\begin{array}{l}\text { Production planning and } \\
\text { control-as-imagined }\end{array}$ & Production planning and control-as-done \\
\hline $\begin{array}{l}\text { The precondition categories for } \\
\text { a construction task are } \\
\text { independent on each other }\end{array}$ & $\begin{array}{l}\text { The preconditions categories for a construction } \\
\text { task depend on each other }\end{array}$ \\
\hline $\begin{array}{l}\text { The process of removing the } \\
\text { constraints is simple }\end{array}$ & $\begin{array}{l}\text { The process of removing the constraints is } \\
\text { complex }\end{array}$ \\
\hline $\begin{array}{l}\text { There is a formal workable } \\
\text { backlog }\end{array}$ & There is not a formal workable backlog \\
\hline $\begin{array}{l}\text { Constraints are identified by } \\
\text { looking for upcoming work } \\
\text { packages }\end{array}$ & $\begin{array}{c}\text { Constraints are identified by looking for upcoming } \\
\text { groups of work packages }\end{array}$ \\
\hline $\begin{array}{l}\text { All constraints are formally } \\
\text { identified and removed }\end{array}$ & $\begin{array}{c}\text { Some constraints are informally identified and } \\
\text { removed - i.e., these constraints are not } \\
\text { anticipated and documented in the planning } \\
\text { meetings }\end{array}$ \\
\hline $\begin{array}{l}\text { All constraints are removed } \\
\text { before starting the work } \\
\text { package }\end{array}$ & $\begin{array}{l}\text { Some constraints are removed while the } \\
\text { execution of the work-package is in-progress }\end{array}$ \\
\hline
\end{tabular}

In the original version of the LPS, the precondition categories for a construction task are typically approached independently. However, this study indicates they are highly 
interdependent, which facilitates variability propagation. The failure to remove one constraint can affect the removal of other constraints for the same work package as occurred in work package B.

Furthermore, in the LPS as-imagined, the processes for removing constraints are not discussed in depth, which suggests that they are tacitly considered as simple. In this study, the large number of functions required to remove constraints (19 for a single work package), combined with the interdependencies and variabilities, suggests that this process is complex. In turn, in the LPS as prescribed by Ballard and Howell (1998), there must be a formal workable backlog, while in the case study, there was not. A workable backlog consists of a set of work packages that have their constraints removed (Ballard, 2000). The lack of that backlog made room for problems such as the scheduling of work packages that still had constraints. On the other hand, if the said workable backlog was in place the number of functions for the removal of constraints would be even larger, demanding even more planning effort from managers. This may partly explain why the workable backlog was not planned.

Another example of the gap between as-imagined and as-done refers to the short-term planning meetings, in which professionals quickly scanned the list of constraints in the look-ahead tool and identified those groups of activities that had no pending constraints - this is in contrast to the as-imagined approach of analyzing constraints for each individual work package. Furthermore, some of the work packages scheduled at the shortterm meetings had no parallel with those discussed during look-ahead planning meetings - this means that the removal of their associated constraints, if occurred, was mostly informal.

However, identifying constraints by looking at groups of activities has two implications. The first one is that some specific constraints for a specific work package can be overlooked. For example, if in a group of activities called "doors", there is a door with a different specification (e.g. a door with a special lock), this can be neglected during the material purchasing managerial function. The other implication is that the total number of constraints may appear to be lower than it is, concealing the time and effort required for their removal. On the other hand, the practice of identifying constraints by looking at groups of activities saves effort as some constraints are associated with more than one work package. Consequently, removing these constraints could result in more than one made-ready work packages. For example, a single managerial function can be performed to provide equipment for several work packages, e.g. a scissor lift can be used for various activities related to the installation of electrical, air conditioning, and fire protection systems.

In addition, there is a difference related to the timing at which the constraints are removed. Different from the original version of the LPS, in which all constraints are removed before the execution of the work package (supporting the creation of a formal workable backlog and related activities), in this study, some constraints were removed while the work package was in-progress.

\section{CONCLUSIONS}

This paper discusses the results of a case study aimed at analyzing the gap between the production planning and control-as-imagined and the production planning and controlas-done. In this investigation, the FRAM was used to model the production planning and control-as-done and to analyze the variability propagation throughout the look-ahead managerial functions. The results suggest differences between what is prescribed by the 
original version of the LPS and how it was applied in practice in the case study, focusing specifically on the look-ahead level. One of the limitations of this study is the fact that it is based on a single case study. Therefore, the results cannot be generalized. Further studies are required to understand if the gaps identified in this study are recurrent on other construction projects and if they reflect fundamental limitations and under specification in the theory of LPS.

\section{REFERENCES}

Ballard, G. (2000). “The last planner system of production control.” PhD Diss., Faculty of Engineering., University of Birminghan., Birmingham, United Kingdom.

Ballard, G., and Howell, G. A. (1998). "Shielding production: essential step in production control." Journal of Construction Engineering and Management., 124(1) 11-17.

Ballard, G., and Howell, G. A. (2003). “An update on last planner.” In: Proc. 11th Ann. Conf. of the Int'l. Group for Lean Construction, Blacksburg, United States.

Ballard, G., and Tommelein, I. D. (2012). "Lean management methods for complex projects." Engineering Project Organization Journal., 2(1-2) 85-96.

Bertelsen, S. (2003). "Construction as a Complex System.” In: Proc. 11th Ann. Conf. of the Int'1. Group for Lean Construction, Blacksburg, United States.

Branski, R., Aurellano, R., and Lima Junior, O. (2010). Metodologia de estudo de caso aplicada à logística. In: Congresso de Pesquisa e Ensino em Transportes, 24., 2010, Salvador. Anais... Salvador, 2010.

Castillo, T., Alarcón, L. F., and Salvatierra, J. L. (2018). "Effects of last planner system practices on social networks and the performance of construction projects." Journal of Construction Engineering and Management., 144(3).

Dekker, S., Bergström, J., Amer-Wåhlin, I., and Cilliers P. (2013). "Complicated, complex, and compliant: best practice in obstetrics." Cognition, Technology and Work., 15(2) 189-195.

Formoso, C.T., Bølviken, T., Rooke, J., and Koskela, L. (2015). "A Conceptual Framework for the Prescriptive Causal Analysis of Construction Waste." In: Proc. 23th Ann. Conf. of the Int'1. Group for Lean Construction, Perth, Australia.

Hamzeh, F., Ballard, G., and Tommelein, I. D. (2012). "Rethinking Lookahead Planning to Optimize Construction Workflow". Lean Construction Journal., 15-34.

Hollnagel, E. (2004). "Barriers and Accident Prevention". Ashgate Publishing., Aldershot, United Kingdom.

Hollnagel, E. (2012). "FRAM, the functional resonance analysis method: modelling complex socio-technical systems. Ashgate.

Hollnagel, E. (2015). "Why is work-as-imagined different from work-as-done?" In: Resilient Health Care: The resilience of everyday clinical work. Ashgate, 249-264.

Hopp, W. J., and Spearman, M. L. (2000). "Factory physics.” McGraw-Hill., New York.

Koskela, L. (2000). "An exploration towards a production theory and its application construction." PhD Diss., University of Technology., Espoo, Finland.

Koskela, L., and Howell, G. A. (2002). "The underlying theory of project management is obsolete." In: Proc. Of the PMI research conference., Seattle, Washington, United States. 
Perkins, L. N., Abdimomunova, L., Valerdi, R., Shields, T., and Nightingale, D. (2010). "Insights from enterprise assessment: How to analyze LESAT results for enterprise transformation." Information Knowledge Systems Management., 9(3-4), 153-174.

Patriarca, R., Falegnami, A., Costantino, F., Di Gravio, G., De Nicola, A., \& Villani, M. L. (2021). WAx: An integrated conceptual framework for the analysis of cyber-sociotechnical systems. Safety science, 136, 105142.

Peñaloza, G. A., Saurin, T. A., \& Formoso, C. T. (2020). Monitoring complexity and resilience in construction projects: The contribution of safety performance measurement systems. Applied ergonomics, 82, 102978.

Soliman, M., and Saurin, T. A. (2020). "Lean-as-imagined differs from lean-as-done: the influence of complexity." Production Planning \& Control., 1-18.

Tommelein, I. D., and Ballard, G. (1997). "Look-ahead planning: screening and pulling." University of California, Berkeley, California, United States. 